\title{
Feverish agitation unveiling a poly poisoning in young children
}

\begin{abstract}
The use of plants is widespread with traditional Moroccan medicine occasionally resulting in poisoning that can be sometimes be fatal, especially in children. The toxicity of medicinal plants and their chemical interactions are mostly unknown by many who use these topical/ oral mixtures. We report the case of 4year old boy, hospitalized in the department of Infectious Diseases P1 at the Children's Hospital of Rabat for 'feverish agitation' (fever and central nervous system irritability) after inhalation of Peganum harmala, ingestion of Chenopodium and nasal application of cade oil. The laboratory tests concluded renal and hepatic failure. The clinical condition improved after 36hours, with renal and hepatic failure resolving after 3 to 6 days.
\end{abstract}

Keywords: peganum harmala, chenopodium, feverish agitation
Volume 2 Issue I - 2015

\author{
Zouiri G,' Radouani MA,' Badrane N, ${ }^{2}$ \\ Assermouh A,' Benbrahim F,' E Hafidi,' \\ Benchekroun S,' Mahraoui $C^{\prime}$ \\ 'Department of Infectious Diseases, Children's hospital of Rabat, \\ Morocco \\ ${ }^{2}$ Poison Control and Pharmacovigilance Center of Morocco, \\ Morocco
}

Correspondence: Zouiri G, Department of Infectious

Diseases, Children $\square$ s Hospital of Rabat, Morocco,

Email dr.zouiri@gmail.com

Received: October 08, 2014 | Published: January 02, 2015
Abbreviations: AST, aspartate aminotransferase; ALT, alanine transaminase; IU, international unit; CT Scan, computed tomography scan

\section{Introduction}

Cade oil, also known as "qatran" by Moroccans, Peganum harmala and Chenopodium are products used frequently and remain unregulated in Moroccan traditional medicine use. We report a case of poisoning by these herbal remedies in a young child, original by its clinical manifestations and how it was caused.

\section{Observation}

We describe this 4year old child, with no past history of note, hospitalized in the department of Infectious Diseases P1 from the Children's Hospital of Rabat for fever and central nervous irritability. The examination and history revealed the child's exposure to the inhalation of Peganum harmala, ingestion of Chenopodium and a nasal application of cade oil about 3 hours before the onset of agitation. This blend of plant was used by the mother to remedy digestive symptoms in her child (food vomiting and diarrhea) evolving since the previous day. Physical examination on admission revealed a fever of $38.5^{\circ} \mathrm{C}$, with a stable hemodynamic and respiratory status.

The neurological examination elicited an agitated patient but conscious. The pupils were symmetrical and reactive to light without glare reflex. Tendon reflexes significantly were reduced with a bilateral babinski. The patient also had a behavioral disorder with a tendency to bite. The rest of the examination was unremarkable.

A brain $\mathrm{CT}$ performed in the emergency room was normal. The lumbar puncture was normal. The laboratory tests revealed renal failure with preserved diuresis (urea $1.74 \mathrm{~g} / 1$ and creatinine $47 \mathrm{mg}$ / 1) and normal renal ultrasound. The liver biochemistry was deranged with an AST of 275IU / 1 and ALT of 107IU / 1 with the protein C reactive measuring $255 \mathrm{mg} / 1$. Presumptive treatment with acyclovir was started and stopped after 24 hours. The patient was put under close clinical and laboratory monitoring.

The neurological signs slowly resolved and were normal 36hours post ingestion. Renal function slowly improved and was normal by 72 hours with liver function returning to normal after 6 days.

\section{Discussion}

The use of plants is widespread in traditional Moroccan medicine resulting poisoning accidents that can be fatal, especially in children. The toxicity of medicinal plants and their possible interactions are unknown by those who use this type of medication mixture.

The plant, Chenopodium ambrosioides, is a herb which may grow to a height of $40 \mathrm{~cm}$. This herb closely resembles the plant from which wormseed oil is derived. It also gives off a strong odor. Flowers are small and green, while seeds are tiny and green when fresh and black when dry. Chenopodium ambrosioides is indigenous to Mexico and South America, and is now found as far north as the New England states in the United States. The plant is cultivated in Brazil, India, and Indonesia; smaller quantities are harvested in France, Central and Eastern Europe. It may be found growing around dwellings and in manured soil as well as being a perennial weed of the roadside and waste places. Symptoms generally start several hours after ingestion of the oil and include nausea, vomiting, abdominal pain, and headache. These symptoms are soon followed by drowsiness, deafness, tinnitus, and in some cases, ataxia, coma, seizures, tachycardia, and death.

Among the essential oils from the most used plants in Morocco we found cade oil extracted from the distillation of the branches of Juniperus oxycedrus. It was used for a long time to treat many skin and parasitic diseases. It contains 17 to $26 \%$ phenol, $12 \%$ of guaiacol, cadinene, other carbides, an alcohol and cadinol. It may be responsible, because of its phenol content, for multi-systemic toxicity. Indeed, it is responsible for severe hypotension; hypothermia, tachypnea and tachycardia. Cade oil intoxication is also responsible for liver and kidney damage. Acute pulmonary edema was also described in the literature. We also observed acute renal failure in our patient. Koruk et al., ${ }^{2}$ reported the presence of renal failure (urea $=114 \mathrm{mg} / \mathrm{dl}$, serum creatinine $=4.7 \mathrm{mg} / \mathrm{dl}$ ) in a man who ingested a spoonful of extract of Juniperus oxycedrus in order to cure his nephrolithiasis. In our patient, hepatic enzymes showed only mild elevation and returned to normal levels on the sixth day, and there was normalization of the urea and creatinin levels 72 hours later. ${ }^{3}$ 
Peganum harmala, commonly known as Syrian rue and Wild rue, is a flowering plant and is widely distributed in the Central Asia, North Africa and Middle East. This plant is known as "Harmal" in Morocco. ${ }^{4}$ The pharmacologically active compounds of P. harmala are several alkaloids, which are found especially in the seeds and the roots. These include $\beta$-carbolines such as: harmine, harmaline (identical with harmidine), harmalol, harman and quinazoline derivatives: vasicine and vasicinone. The alka-loidal content of the unripe seeds is less than the ripe ones. ${ }^{5}$

There are few reports on its human toxic effects and symptoms. Saiah et al. reported a case of overdose with $P$. harmala in a young lady (aged 27years) who took $50 \mathrm{~g}$ of seeds of this plant for the treatment of amenorrhea. A few minutes after ingestion of seeds in a cup of coffee, signs of intoxication were observed and the patient was taken to hospital. The signs of $P$. harmala overdose comprised of hallucinations and neuro-sensorial syndromes, bradycardia and GI disturbances including nausea and vomiting. Para-clinical tests showed that the function of the liver and kidney to be normal and the patient had a normal hematological picture. She was discharged from hospital a few hours later after signs of intoxication had disappeared.

Our patient was poly intoxicated by nasal application of cade oil, ingestion of Chenopodium and inhalation by $P$. harmala with neurological manifestations (fever and central nervous irritability), liver and kidney failure. No cases of fever and central nervous irritability have been reported to date due to poisoning by these products, especially since poisoning by nasal application of cade oil is very rare and has never led to a severe symptomatology. We hypothesize that the severity of symptoms seen in our case were due to simultaneous use of these herbal remedies leading to the manifestation of these serious complications, thankfully resolving over time.

\section{Acknowledgments}

None.

\section{Conflicts of interest}

Author declares there are no conflicts of interest.

\section{Funding}

None.

\section{References}

1. http://www.capm.ma/

2. Koruk ST, Ozyilkan E, Kaya P, et al. Juniper tar poisoning. Clin Toxicol (Phila). 2005;43(1):47-49.

3. Sanae Achour, Sana Abourazzak, Abdelrhani Mokhtari, et al. Juniper tar (cade oil) poisoning in new born after a cutaneous application. BMJ Case Reports. 2011.

4. Cordell GA, Beecher CW, Pezzuto JM. Can ethnopharmacology contribute to the development of new anticancer drugs? $J$ Ethnopharmaocol. 1991;32(1-3):117-133.

5. Peganum harmala. UAR J Vet Sci .7(1):71-85.

6. Ben Salah N, Amamou M, Jerbi Z, et al. A case of overdose with Peganum harmala L. J Toxicol Clin Exp. 1986;6(5):319-322. 